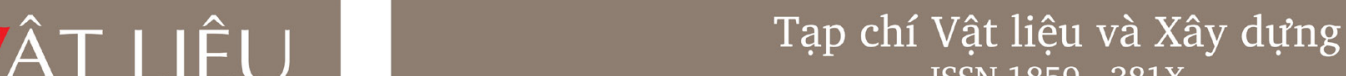 ISSN 1859 - 381X \\ Website: www.jomc.vn
}

\section{Nghiên cứu phương pháp quản trị khoản phải thu để giảm thiểu rủi ro tín dụng thương mại trong các công ty kinh doanh vật liệu xây dựng}

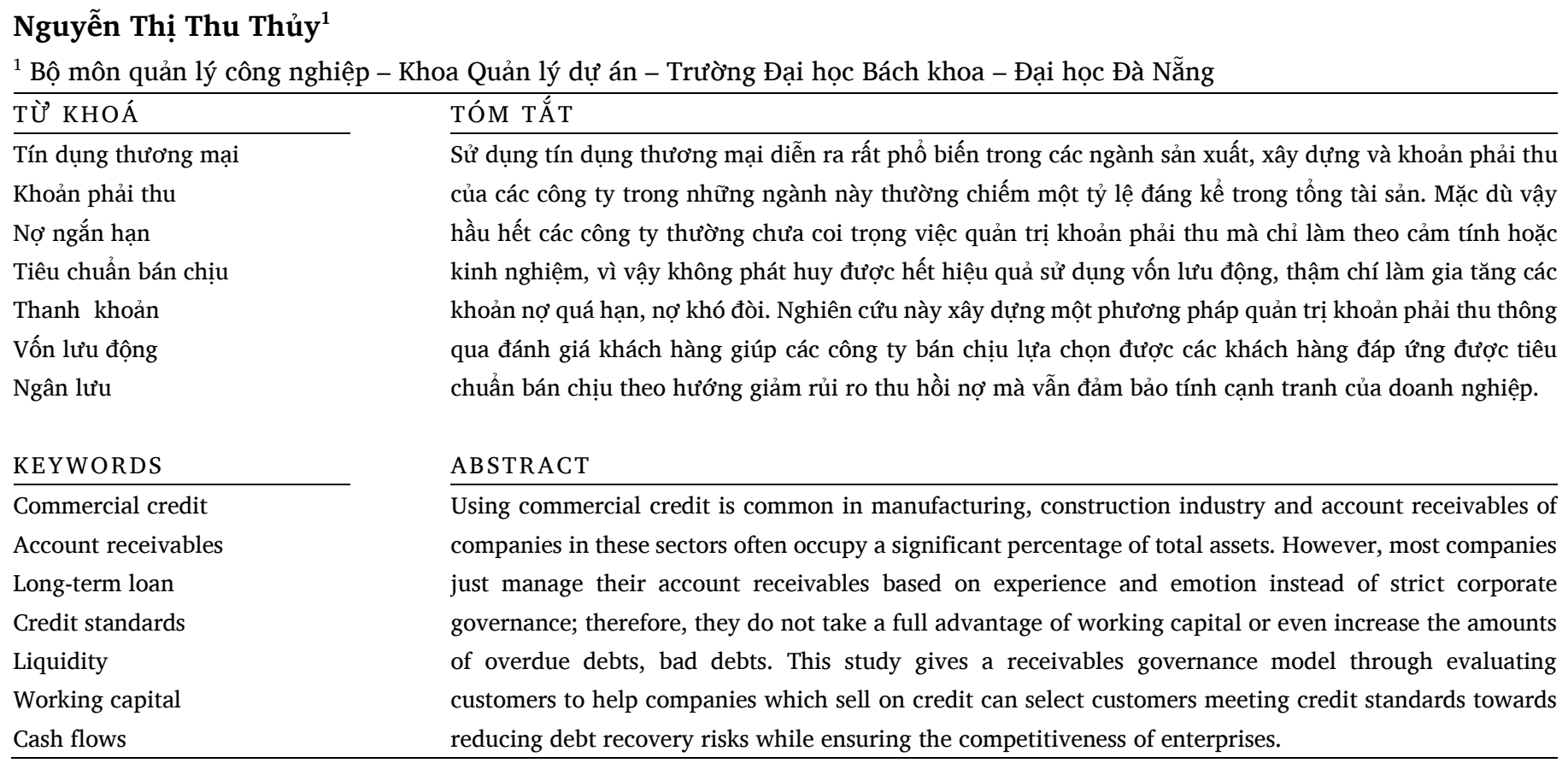

\section{1. Đặt vấn đề}

Nền kinh tế thị trường càng phát triển thì các quan hệ tín dụng ngày càng trở nên đa dạng và phức tạp. Sự phát sinh nợ là một yếu tố tất nhiên trong hoạt động kinh doanh, trong đó bao gồm cả tín dụng ngân hàng và tín dụng thương mại. Trong điều kiện nền kinh tế đang gặp nhiều khó khăn do dịch bệnh kéo dài, nhiều doanh nghiệp đang phải đối mặt với mức độ rủi ro tín dụng rất cao, trong đó rủi ro về tổn thất nợ khó đòi là một trong những nhân tố cần được kiểm soát chặt chẽ. Xét về cơ cấu chi phí trong ngành xây dựng, nguyên vật liệu chiếm tỷ trọng lớn trong tổng giá trị công trình và các đơn hàng mua chịu thường có giá trị lớn. Khi khách hàng chậm trễ trong việc trả nợ hoặc thậm chí không trả được nợ sẽ ảnh hưởng rất lớn đến dòng ngân quỹ của công ty bán chịu. Tổn thất do nợ đọng giữa các doanh nghiệp gia tăng sẽ làm suy giảm năng lực cạnh tranh của các doanh nghiệp, thậm chí dẫn tới nguy cơ phá sản.

Một trong những yếu tố quan trọng của chính sách bán chịu là xây dựng tiêu chuẩn bán chịu, theo đó công ty sẽ lựa chọn đối tượng khách hàng có mức độ tin cậy cao đưa vào danh sách bán chịu để giảm thiểu nợ xấu, nợ quá hạn. Điều này không có nghĩa là đưa ra một bộ các tiêu chí khắt khe đối với khách hàng mà phải đánh giá được tầm quan trọng của từng tiêu chí qua đó xem xét mức độ đáp ứng của khách hàng đối với mỗi tiêu chí.

Như vậy, mục tiêu của nghiên cứu này là: Xây dựng một phương pháp đánh giá các tiêu chí khách hàng qua đó chọn lựa các khách hàng phù hợp để cấp tín dụng thương mại nhằm giảm thiểu chi phí của công ty bán chịu.

\section{Vai trò của khoản phải thu trong hoạt động kinh doanh}

2.1. Nguyên nhân hình thành khoản phải thu

Khoản phải thu (Acount receivables) là một thành phần của vốn luân chuyển, biểu thị khoản tiền mà khách hàng nợ công ty do mua chịu hàng hóa hoặc dịch vụ.

Việc hình thành quan hệ tín dụng thương mại giữa các doanh nghiệp sẽ tạo ra các doanh nghiệp bán chịu và các doanh nghiệp mua chịu. Đối với doanh nghiệp bán chịu thì lợi ích họ cung cấp cho khách hàng là quyền sử dụng vốn (dưới dạng hàng hóa, dịch vụ) trong một khoảng thời gian nào đó, và khoản nợ của khách hàng chính là khoản phải thu của công ty bán chịu. 


\subsection{Tác dụng của khoản phải thu}

Tín dụng thương mại là một trong những phương án tài trợ được rất nhiều công ty (ở vai trò người mua) lựa chọn. Những rủi ro khách quan (như tình trạng dịch bệnh toàn cầu) có tác động bất lợi đến hoạt động kinh doanh và làm ảnh hưởng đến năng lực tài chính của các doanh nghiệp, vì vậy tín dụng thương mại là một "cứu cánh" để duy trì sản xuất trong tình trạng thiếu vốn. Đặc biệt trong ngành xây dựng, phần lớn các nhà thầu xây dựng coi việc cho mua chịu như là một điều kiện tất yếu để lựa chọn nhà cung cấp. Do đó để tạo mối quan hệ lâu dài với khách hàng cũ và thu hút được nhiều khách hàng mới, các công ty cung cấp vật liệu xây dựng (ở vai trò người bán) đều dựa vào chính sách cho trả chậm. Thông thường ở các công ty, khoản tín dụng thương mại có xu hướng cao hơn tín dụng ngân hàng. Theo một số nghiên cứu[1], con số này là hai lần.

So với tín dụng ngân hàng, tín dụng thương mại có các lợi thế sau:

Đối với người mua:

- Không cần tài sản thế chấp.

- Có thể duy trì hoạt động sản xuất kinh doanh ngay cả khi thiếu vốn.

- Các điều kiện mua chịu linh hoạt và có thể thỏa thuận với người bán dựa vào uy tín của người mua.

Đối với người bán:

- Làm gia tăng doanh số, giảm tồn kho.

- Làm tăng khả năng cạnh tranh và thu hút khách hàng.

- Giúp nắm được thông tin khách hàng.

- Củng cố danh tiếng, tăng giá trị cổ phiếu của công ty.

Chính sách này buộc nhà cung cấp nguyên vật liệu phải dùng vốn lưu động của mình để tài trợ cho khách hàng trong một khoảng thời gian nhất định. Vì vậy có thể nói chấp nhận cho khách hàng mua chịu tức là chấp nhận đánh đổi giữa việc tăng doanh thu và rủi ro thu hồi nợ.

\section{Khảo sát tình hình quản lý khoản phải thu}

\section{1. Đối tượng và phạm vi khảo sát}

- Thời gian khảo sát từ tháng 10/2020 đến tháng $3 / 2021$;

- Đối tượng khảo sát là các doanh nghiệp kinh doanh vật liệu xây dựng có quy mô vừa và nhỏ trên địa bàn thành phố Đà Nẵng;

- Quy mô là 250 phiếu khảo sát (trong đó có 225 phiếu hợp lệ).

\subsection{Phân tích kết quả khảo sát}

a. Về quy mô khoản nợ (Bảng 3.1)
- Tất cả các doanh nghiệp được khảo sát đều có khoản phải thu.

- Số lượng doanh nghiệp có khoản phải thu nằm trong khoảng từ 200 đến dưới 500 triệu đồng chiểm tỷ lệ cao nhất (48 \%) trong số các doanh nghiệp được khảo sát.

- Số lượng doanh nghiệp có khoản phải thu trên 1 tỷ đồng chiểm tỷ lệ thấp nhất $(6,67 \%)$ trong số các doanh nghiệp được khảo sát (điều này có thể được giải thích là do các doanh nghiệp được khảo sát có quy mô vừa và nhỏ nên khoản phải thu của họ không lớn lắm).

Bảng 3.1.

Số lượng doanh nghiệp và quy mô khoản nợ.

\begin{tabular}{|l|c|c|}
\hline Độ lớn khoản nợ & $\begin{array}{c}\text { Số lượng } \\
\text { doanh nghiệp }\end{array}$ & Tỷ lệ (\%) \\
\hline Dưới 200 triệu đồng & 63 & 28,00 \\
\hline Từ 200 đến dưới 500 triệu đồng & 108 & 48,00 \\
\hline Từ 500 triệu đồng đến dưới 1 tỷ đồng & 39 & 17,33 \\
\hline Từ 1 tỷ đồng trở lên & 15 & 6,67 \\
\hline TổNG CộNG & 225 & 100 \\
\hline
\end{tabular}

b. Về tỷ trọng khoản phải thu so với tài sản ngắn hạn (Bảng 3.2)

Khoản phải thu chiếm tỷ lệ tương đối cao trong kết cấu tài sản ngắn hạn của công ty bán chịu (phổ biến ở vào khoảng $20 \%$ đến 50 \%). Tỷ lệ này càng cao khả năng thanh khoản của doanh nghiệp càng giảm, hay nói cách khác việc nợ đọng quá nhiều ở khách hàng làm suy giảm năng lực tài chính của doanh nghiệp.

Bảng 3.2.

Tỷ trọng khoản phải thu trong tài sản ngắn hạn.

\begin{tabular}{|c|c|c|}
\hline $\begin{array}{c}\text { Tỷ trọng khoản phải thu so } \\
\text { với tài sản ngắn hạn (\%) }\end{array}$ & $\begin{array}{c}\text { Số lượng doanh } \\
\text { nghiệp }\end{array}$ & Tỷ lệ (\%) \\
\hline Dưới $20 \%$ & 27 & 12,00 \\
\hline Từ $20 \%$ đến dưới $30 \%$ & 83 & 36,89 \\
\hline Từ $30 \%$ đến dưới $40 \%$ & 78 & 34,67 \\
\hline Từ $40 \%$ đến dưới $50 \%$ & 34 & 15,11 \\
\hline Từ $50 \%$ trở lên & 3 & 1,33 \\
\hline TổNG CộNG & $\mathbf{2 2 5}$ & $\mathbf{1 0 0}$ \\
\hline
\end{tabular}

c. Về khoản phải thu quá hạn (Bảng 3.3)
Bảng 3.3. 
Số lượng doanh nghiệp và khoản nợ quá hạn.

\begin{tabular}{|l|c|c|}
\hline \multicolumn{1}{|c|}{ Độ lớn khoản nợ quá hạn } & $\begin{array}{c}\text { Số lượng doanh } \\
\text { nghiệp }\end{array}$ & Tỷ lệ (\%) \\
\hline $\begin{array}{l}\text { Không có nợ quá hạn hoặc nợ } \\
\text { quá hạn dưới một tháng }\end{array}$ & 93 & 41,33 \\
\hline Dưới 100 triệu đồng & 52 & 23,11 \\
\hline Từ 100 đến dưới 200 triệu đồng & 30 & 13,33 \\
\hline $\begin{array}{l}\text { Từ } 200 \text { triệu đồng đến dưới 300 } \\
\text { triệu đồng }\end{array}$ & 44 & 19,56 \\
\hline Từ 300 triệu đồng trở lên & 6 & 2,67 \\
\hline \multicolumn{1}{|c|}{ TốNG CộNG } & $\mathbf{2 2 5}$ & $\mathbf{1 0 0}$ \\
\hline
\end{tabular}

Có 132 công ty trong số 225 các công ty được khảo sát (chiếm tỷ lệ 58,67 \%) có khoản phải thu quá hạn, nhưng ở mức độ khác nhau. Số liệu này chỉ tính cho các khoản nợ có thời gian quá hạn từ một tháng trở lên.

\section{d. Về thời gian quá hạn của các khản nợ (Bảng 3.4)}

Trong 132 công ty có khoản nợ quá hạn (tính cho các khoản nợ có thời gian quá hạn từ một tháng trở lên) thì mức độ quá hạn cũng khác nhau. Có một số công ty đang phải "tài trợ" cho những đơn hàng quá hạn đến trên một năm, vượt xa so với thời hạn trả chậm ghi trong hợp đồng.

Bảng 3.4.

Thời gian quá hạn của các khoản nợ.

\begin{tabular}{|l|c|c|}
\hline $\begin{array}{c}\text { Thời gian quá hạn của các khoản } \\
\text { nợ }\end{array}$ & $\begin{array}{c}\text { Số lượng doanh } \\
\text { nghiệp }\end{array}$ & Tỷ lệ (\%) \\
\hline Dưới 3 tháng & 20 & 15,15 \\
\hline Từ 3 tháng đến dưới 6 tháng & 54 & 40,91 \\
\hline Từ 6 tháng đến dưới 1 năm & 33 & 25,00 \\
\hline Từ một năm trở lên & 25 & 18,94 \\
\hline TổNG CộNG & $\mathbf{1 3 2}$ & $\mathbf{1 0 0}$ \\
\hline
\end{tabular}

Kết quả khảo sát trên cho thấy tín dụng thương mại đang đối mặt với nguy cơ nợ quá hạn, nợ khó đòi. Nguy cơ này không còn tiềm ẩn nữa mà hiện diện khá rõ nét cả về quy mô khoản nợ, thời gian quá hạn và tính "xâu chuỗi", vì không ít công ty là chủ nợ của người này nhưng lại là con nợ của người khác.

\section{Xây dựng phương pháp đánh giá tiêu chuẩn khách hàng mua chịu}

4.1. Quyết định chính sách bán chịu
Các quyết định về khoản phải thu của doanh nghiệp được xem xét dựa trên hiệu số lợi ích - chi phí là số dương, hay nói cách khác công ty bán chịu sẽ chấp thuận thêm một khách hàng mua chịu nếu biên lợi nhuận vẫn còn là số dương.

\subsection{Xác định tiêu chuẩn bán chịu}

Tiêu chuẩn bán chịu được xác định theo bộ tiêu chí $5 \mathrm{C}$ để xây dựng mô hình nghiên cứu. Nội dung cụ thể của mỗi tiêu chí như sau:

a. Tư cách khách hàng - Character

Tư cách là yếu tố đầu tiên, rất quan trọng trong đánh giá uy tín khách hàng. Tư cách là một tập hợp bao gồm:

+ Đạo đức.

+ Chất lượng và khả năng quản lý.

+ Lòng tin.

+ Trách nhiệm đối với khoản nợ và độ sẵn lòng trả nợ.

Khi phân tích yếu tố tư cách, người phân tích cần dựa vào dữ liệu quá khứ về việc trả nợ và những đánh giá của các đối tác khác của khách hàng.

b. Vốn-Capital

Vốn được hiểu là giá trị tài sản ròng, hay chênh lệch giữa tổng tài sản và nợ phải trả. Đó là những gì còn lại nếu phải thanh lý tài sản để trả nợ.

\section{c. Khả năng trả nợ - Capacity}

Khả năng trả nợ là khả năng tạo ra dòng ngân lưu từ hoạt động kinh doanh để trả nợ khi đến hạn. Công cụ đánh giá khả năng trả nợ tốt nhất là các báo cáo ngân lưu trong quá khứ và báo cáo ngân lưu dự toán.

\section{d. Điều kiện kinh doanh - Condition}

Điều kiện kinh doanh có thể bao gồm các điều kiện khách quan như: + Bối cảnh kinh tế. + $\quad$ + Môi trường kinh doanh.

+ Tình hình chung của ngành. + Lý do nhu cầu mua chịu.

\section{e. Tài sản bảo đảm - Collateral}

Trong quan hệ mua bán chịu, tài sản bảo đảm không được coi là tiêu chí quan trọng. Người bán và người mua có thể thỏa thuận về việc 
dùng tài sản để đảm bảo cho khoản nợ, tuy nhiên trên thực tế rất ít trường hợp bán chịu có tài sản bảo đảm.

\subsection{Phân tích định lượng}

a. Đề xuất mô hình nghiên cứu

Sau khi nghiên cứu định tính, mô hình nghiên cứu đề xuất các yếu tố ảnh hưởng đến khoản phải thu của doanh nghiệp kinh doanh vật liệu xây dựng được thể hiện trong Hình 4.1.

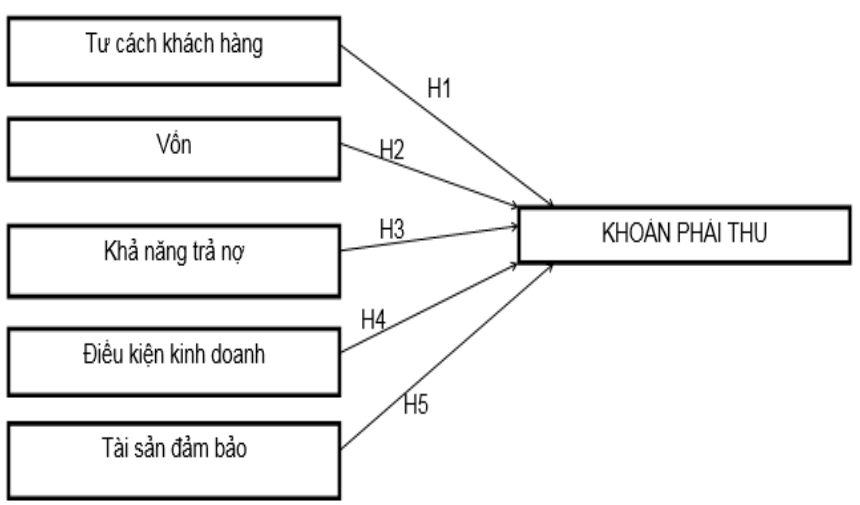

Hình 4.1. Mô hình đề xuất các yếu tố tác động đến khoản phải thu của một doanh nghiệp.

b. Các giả thuyết

Giả thuyết H1: Tư cách khách hàng có mối quan hệ dương với khoản phải thu của doanh nghiệp.

Giả thuyết H2: Vốn có mối quan hệ dương với khoản phải thu của doanh nghiệp.

Giả thuyết H3: Khả năng trả nợ có mối quan hệ dương với khoản phải thu của doanh nghiệp.

Giả thuyết H4: Điều kiện kinh doanh có mối quan hệ dương với khoản phải thu của doanh nghiệp.

Giả thuyết H5: Tài sản đảm bảo có mối quan hệ dương với khoản phải thu của Doanh nghiệp.

c. Xây dựng thang đo

Thang đo được xây dựng dựa trên các yếu tố có thể đánh giá bằng khảo sát. Các yếu tố Tư cách khách hàng, Vốn, Khả năng trả nợ, Điều kiện kinh doanh, Tài sản bảo đảm là các biến độc lập; Khoản phải thu là biến phu thuộc.
Bảng 4.1.

Thang đo yếu tố ảnh hưởng đến khoản phải thu của doanh nghiệp vật liệu xây dựng.

\begin{tabular}{|c|c|}
\hline Biến quan sát & Ý nghĩa các biến quan sát \\
\hline \multirow{3}{*}{$\begin{array}{l}\text { KH: Tư cách } \\
\text { khách hàng }\end{array}$} & $\begin{array}{l}\text { KH1: Uy tín và Chất lượng quản lý của công ty khách } \\
\text { hàng }\end{array}$ \\
\hline & KH2: Tỷ lệ các đơn hàng được thanh toán đúng hạn \\
\hline & KH3: Trách nhiệm và độ sã̃n lòng trả nợ \\
\hline \multirow{3}{*}{ V: Vốn } & V1: Giá trị tổng tài sản \\
\hline & V2: Chênh lệch giữa tổng tài sản và nợ phải trả \\
\hline & V3: Giá trị tài sản ngắn hạn \\
\hline \multirow{3}{*}{$\begin{array}{l}\text { TN: Khả năng } \\
\text { trả nợ }\end{array}$} & $\begin{array}{l}\text { TN1: Dòng ngân lưu từ hoạt động kinh doanh trong } \\
\text { quá khứ }\end{array}$ \\
\hline & $\begin{array}{l}\text { TN2: Dòng ngân lưu từ hoạt động kinh doanh theo dự } \\
\text { toán }\end{array}$ \\
\hline & TN3: Tính thanh khoản của tài sản ngắn hạn \\
\hline \multirow{3}{*}{$\begin{array}{l}\text { DK: Điều kiện } \\
\text { kinh doanh }\end{array}$} & DK1: Bối cảnh kinh tế và môi trường kinh doanh \\
\hline & $\begin{array}{l}\text { DK2: Tình hình kinh doanh của ngành vật liệu xây } \\
\text { dựng }\end{array}$ \\
\hline & DK3: Nhu cầu mua chịu \\
\hline \multirow{3}{*}{$\begin{array}{l}\text { TS: Tài sản đảm } \\
\text { bảo }\end{array}$} & TS1: Giá trị tài sản có thể đảm bảo cho các khoản nợ \\
\hline & $\begin{array}{l}\text { TS2: Tỷ lệ tài sản cố định và tài sản lưu động của } \\
\text { công ty }\end{array}$ \\
\hline & $\begin{array}{l}\text { TS3: Cam kết của khách hàng trong việc bán tài sản } \\
\text { để trả nợ }\end{array}$ \\
\hline \multirow[b]{2}{*}{$\begin{array}{l}\text { KPT: Khoản } \\
\text { phải thu }\end{array}$} & KPT1: Mức độ an toàn của khoản phải thu \\
\hline & $\begin{array}{l}\text { KPT2: Ảnh hưởng của khoản phải thu đến doanh thu } \\
\text { của người bán }\end{array}$ \\
\hline
\end{tabular}

Các điều kiện ràng buộc:

$K H 2 \geq 0 ; V 1 \geq 0 ; V 3>0$

$T N 1 \geq 0 ; \quad T N 2 \geq 0$

\subsection{Kết quả khảo sát và nghiên cứu}

a. Kết quả mô hình đo lường

Đối với mô hình đo lường, sự phù hợp của thang đo được xác định thông qua kiểm tra độ tin cậy bằng Cronbach's Alpha, phân tích nhân tố khám phá EFA.

Trước khi đưa các yếu tố vào phân tích nhân tố, cần thiết phải kiểm định độ tin cậy của thang đo các yếu tố này. Theo nhiều nhà nghiên cứu, thang đo có hệ số Cronbach's Alpha lớn hơn 0,7 trở lên là sử dụng được. (Nunally, 1978; Peterson, 1994; Slater, 1995; dẫn theo Hoàng Trọng và Chu Nguyễn Mộng Ngọc, 2005) [6]. Kết quả cho thấy 
thang đo của cả 15 biến quan sát với 5 nhân tố đều đảm bảo độ tin cậy với hệ số Cronbach's Alpha lớn hơn 0,7.

\section{Bảng 4.2.}

Thang đo nhân tố tác động đến khoản phải thu của doanh nghiệp vật liệu xây dựng.

\begin{tabular}{|c|c|c|c|c|c|}
\hline \multicolumn{6}{|c|}{ Ma trận nhân tố } \\
\hline & \multicolumn{5}{|c|}{ Nhân tố } \\
\hline & 1 & 2 & 3 & 4 & 5 \\
\hline DK2 & 0,947 & & & & \\
\hline DK1 & 0,938 & & & & \\
\hline DK3 & 0,928 & & & & \\
\hline TN2 & & 0,932 & & & \\
\hline TN1 & & 0,917 & & & \\
\hline TN3 & & 0,908 & & & \\
\hline TS2 & & & 0,898 & & \\
\hline TS1 & & & 0,881 & & \\
\hline TS3 & & & 0,848 & & \\
\hline V2 & & & & 0,839 & \\
\hline V1 & & & & 0,837 & \\
\hline V3 & & & & 0,786 & \\
\hline KH2 & & & & & 0,831 \\
\hline KH1 & & & & & 0,797 \\
\hline KH3 & & & & & 0,780 \\
\hline
\end{tabular}

Kết quả phân tích nhân tố EFA được chấp nhận do tổng phương sai trích là $77,207 \%>50 \%$ và giá trị riêng (Eigenvalue) là $1,515>1$.

\section{b. Kết quả kiểm định tương quan Pearson và mô hình hồi quy tuyến tính bội}

\section{- Kiểm định tương quan Pearson:}

Để đánh giá ảnh hưởng của các nhân tố lên khoản phải thu, chúng ta sử dụng mô hình hồi quy bội, trong đó 5 nhân tố từ kết quả phân tích trên đây là 5 biến độc lập tương ứng. Biến phụ thuộc phản ánh khoản phải thu của doanh nghiệp. Mô hình hồi quy được viết như sau:

$$
\mathrm{KPT}=\beta 1 * \mathrm{KH}+\beta 2 * \mathrm{~V}+\beta 3 * \mathrm{TN}+\beta 4 * \mathrm{DK}+\beta 5^{*} \mathrm{TS}
$$

Tương quan Pearson phản ánh mối quan hệ giữa từng cặp biến và tham khảo xem có hiện tượng đa cộng biến giữa các biến hay không. Sau khi phân tích thì sig giữa biến phụ thuộc KPT và các biến độc lập đều bé hơn 0,05 nên có mối quan hệ tương quan tuyến tính giữa biến phụ thuộc và các biến độc lập.
- Mô hình hồi quy tuyến tính bội

Mô hình hồi quy mà chúng ta đang nghiên cứu phải giải thích được hành vi của biến phụ thuộc. Mô hình có một biến phụ thuộc với hai hoặc nhiều biến độc lập được gọi là hồi quy bội. Kết quả phân tích hồi quy tuyến tính bội thể hiện ở Bảng 4.3.

\section{Bảng 4.3.}

Kết quả phân tích hồi quy tuyến tính.

\begin{tabular}{|c|c|c|c|c|c|}
\hline Mô hình & $\begin{array}{c}\text { Hệ số hồi quy } \\
\text { chuẩn hóa }\end{array}$ & \multirow{2}{*}{$\mathrm{t}$} & $\begin{array}{c}\text { Giá trị } \\
\text { Sig. }\end{array}$ & \multicolumn{2}{|c|}{$\begin{array}{c}\text { Thống kê đa cộng } \\
\text { tuyến }\end{array}$} \\
\cline { 2 - 5 } & Beta & & & $\begin{array}{c}\text { Độ chấp } \\
\text { nhận }\end{array}$ & $\begin{array}{c}\text { Hệ số phóng } \\
\text { đại phương } \\
\text { sai VIF }\end{array}$ \\
\hline 1(Hằng số) & & 2,424 & 0,016 & & \\
\hline KH & 0,36 & 11,045 & 0 & 0,912 & 1,096 \\
\hline V & 0,38 & 11,946 & 0 & 0,955 & 1,047 \\
\hline TN & 0,631 & 18,467 & 0 & 0,827 & 1,209 \\
\hline DK & 0,048 & 1,463 & 0,145 & 0,907 & 1,102 \\
\hline TS & 0,163 & 4,947 & 0 & 0,886 & 1,129 \\
\hline \multicolumn{7}{|c|}{ Giá trị R bình phương hiệu chỉnh: 0,803} \\
\hline Hệ số Durbin-Watson: 2,092 \\
\hline
\end{tabular}

Ta có:

- $\mathrm{R}^{2}$ hiệu chỉnh $=80,3 \%>50 \%$, các biến độc lập ảnh hưởng đến 80,3 \% sự thay đổi của biến phụ thuộc.

- Hệ số Durbin-Watson tiến về 2 cho thây không có sự tương quan chuỗi bậc nhất.

- Do sig $\mathrm{DK}_{\mathrm{DK}}>0,05$ nên loại nhân tố ra khỏi mô hình.

- VIF của tất cả nhân tố đều nhỏ hơn 2 nên không xảy ra hiện tượng đa cộng tuyến giữa các biến.

Hàm hồi quy được viết như sau:

$\mathrm{KPT}=0,36 * \mathrm{KH}+0,38 * \mathrm{~V}+0,631 * \mathrm{TN}+0,163 * \mathrm{TS}$

Các hệ số trong phương trình hồi quy đều mang dấu dương thể hiện cả 4 nhân tố đều có ảnh hưởng cùng chiều đến hoạt động kinh doanh của doanh nghiệp.

\subsection{Nhận xét kết quả nghiên cứu và đề xuất}

a. Nhận xét kết quả nghiên cứu

Từ kết quả nghiên cứu trên có thể đưa ra các nhận xét sau: - Khả năng trả nợ $(\beta 3=0,631)$ được chú trọng nhiều nhất khi đánh giá khách hàng mua chịu, công cụ đánh giá khả năng trả nợ tốt nhất là các báo cáo ngân lưu trong quá khứ và báo cáo ngân lưu dự toán. 
- Nhân tố vốn $(\beta 2=0,38)$ được đánh giá thông qua tổng tài sản của công ty và tổng số nợ mà công ty đang có. Đây là yếu tố thể hiện khả năng "trang trải” nợ với giả thiết tài sản của công ty được bán để thanh toán nợ.

- Tư cách khách hàng $(\beta 1=0,36)$ rất quan trọng trong việc đánh giá uy tín, thái độ của khách hàng đối với việc trả nợ đúng hạn.

- Tài sản đảm bảo $(\beta 4=0,163)$ là tiêu chí không mấy quan trọng, nó được xem xét để bổ sung thêm cho tiêu chí vốn và năng lực trả nợ của khách hàng.

c. Đề xuất

Dựa trên cơ sở phân tích tài chính và những thông tin phi tài chính, người phân tích sẽ đánh giá khách hàng là có đáp ứng tiêu chuẩn bán chịu hay không. Những khách hàng mới thường được cấp một hạn mức tín dụng thấp và được theo dõi trong một thời gian nhất định, hoặc phải có tài sản bảo đảm, hoặc phải có một ngân hàng bảo lãnh.

Quy trình ra quyết định bán chịu được mô hình hóa theo sơ đồ sau:

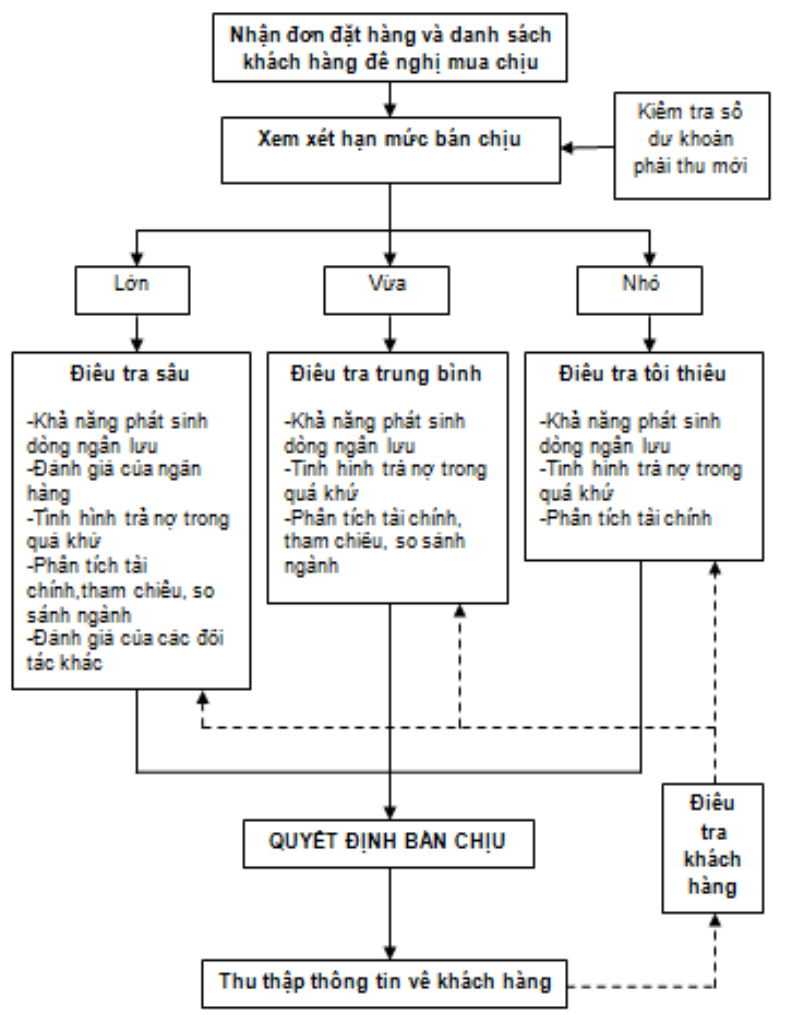

Hình 4.2. Quy trình ra quyết định bán chịu.

\section{Thảo luận về kết quả nghiên cứu}

Trong phạm vi của đề tài này chúng tôi đã nghiên cứu các yếu tố thuộc về tiêu chuẩn khách hàng giúp các công ty bán chịu có thể lựa chọn được đối tượng khách hàng phù hợp nhằm làm tăng độ an toàn của khoản phải thu, nâng cao hiệu quả sử dụng vốn lưu động và tăng khả năng cạnh tranh của công ty. Kết quả đạt được phù hợp với mục tiêu đề ra. Tuy nhiên còn một khía cạnh chưa được xem xét, đó là trường hợp một công ty vừa là chủ nợ vừa là con nợ. Trong thực tế một công ty có thể vay của một đối tác để tài trợ cho một đối tác khác.

\section{Kết luận}

Quản trị tốt khoản phải thu có thể làm tăng giá trị doanh nghiệp, việc này đòi hỏi các công ty áp dụng chính sách bán chịu phải đánh giá đúng tầm quan trọng của khoản phải thu và xác định được mục tiêu của quản trị khoản phải thu. Khi đã xây dựng được một chính sách bán chịu phù hợp, công ty cần tuân thủ đúng các điều khoản của nó và thường xuyên theo dõi, đánh giá những thay đổi từ phía khách hàng cũng như môi trường kinh doanh để có những điều chỉnh cần thiết trong chính sách quản trị khoản phải thu.

\section{Tài liệu tham khảo}

[1]. Nguyễn Tấn B., Quản trị tài chính ngắn hạn. Tp. Hồ Chí Minh: NXB Thống kê, 2011.

[2]. Nguyễn Minh K., Ngô Kim P., Diệp D., Trần Thị Kim C., and FETP, "Phân tích tài chính.” Chương trình Giảng dạy Kinh tế Fulbright, 2010.

[3]. E. F. Brigham and J. F. Houston, Fundamentals of Financial Management. Cengage Learning, 2021.

[4]. "CEO - Giám Đốc Điều Hành Chuyên Nghiệp Tổ Chức Giáo Dục Đào Tạo PTI." https://www.giamdocdieuhanh.vn (accessed Oct. 20, 2021).

[5]. hotrospss, "Tổng hợp link download phần mềm SPSS, AMOS - Hỗ Trợ SPSS." https://phantichspss.com/tong-hop-link-download-phan-mem-spssamos.html (accessed Oct. 20, 2021).

[6]. hotrospss, "Phân tích độ tin cậy cronbach's alpha - Hỗ Trợ SPSS." https://phantichspss.com/phan-tich-do-tin-cay-cronbachs-alpha.html (accessed Mar. 225, 2021).

[7]. Nguyễn Minh K., Khoa sau đại học - Đại học mở TP. Hồ Chí Minh, and chương trình giảng dạy kinh tế Fulbright, Quản trị rủi ro tài chính. 2014. 